\title{
Physical and Antigenic Heterogeneity in the Flagellins of Listeria monocytogenes and $L$. ivanovii
}

\author{
By M. PEEL, W. DONACHIE* AND A. SHAW \\ Moredun Research Institute, 408 Gilmerton Road, Edinburgh EH17 7JH, UK
}

(Received 11 January 1988; revised 25 April 1988)

\begin{abstract}
Listeria monocytogenes serotypes $4 \mathrm{a}, 4 \mathrm{~b}$ and 7 , and L. ivanovii, all grown at $20^{\circ} \mathrm{C}$, wère negatively stained and examined by electron microscopy. Crude extracts of the cell surface of $L$. monocytogenes serotypes $1 / 2 \mathrm{~b}, 3 \mathrm{~b}, 3 \mathrm{c}, 4 \mathrm{a}, 4 \mathrm{~b}, 4 \mathrm{~d}$ and 7 and of $L$. ivanovii (all grown at $20^{\circ} \mathrm{C}$ ) were examined by SDS-PAGE and Western blotting using (i) affinity-purified polyclonal monospecific antibody, and (ii) monoclonal antibody, each raised against $29 \mathrm{kDa}$ flagellin of serotype $4 \mathrm{~b}$. No flagella were seen on serotype 7 by electron microscopy and no flagellin was detected in crude cell surface extracts of serotype 7 either in silver-stained gels or in Western blots. The monospecific polyclonal antibody detected flagellins of approximate molecular mass $29 \mathrm{kDa}$ in each of the seven flagellate strains including $L$. ivanovii. The monoclonal antibody detected $29 \mathrm{kDa}$ flagellin in serotypes $1 / 2 \mathrm{~b}, 3 \mathrm{~b}, 4 \mathrm{a}, 4 \mathrm{~b}$ and $4 \mathrm{~d}$, but not the flagellins of serotype $3 \mathrm{c}$ or L. ivanovii, which had a slightly lower molecular mass. Following prolonged electrophoresis of crude flagellar extracts the $29 \mathrm{kDa}$ complex was resolved into three closely migrating bands. In a heterologous system using serotype $1 / 2 \mathrm{~b}$ crude flagellar extract, all three bands were detected using the polyclonal antibody whereas only two bands were detected by the monoclonal antibody. It is concluded that polyclonal anti-flagellin antibodies are not useful tools with which to distinguish serotypes of $L$. monocytogenes sensu lato in immunoblotting, but that differences can be determined using a monoclonal antibody directed against particular components of the flagellar complex. These differences did not fully correspond to those anticipated from results of agglutination tests.
\end{abstract}

\section{INTRODUCTION}

Listeria monocytogenes sensu lato is an important pathogen of both man and domestic animals (Gray \& Killinger, 1966) and is serotyped by agglutinating reactions between bacterial cell antigens and serotype-specific antisera (Seeliger \& Hohne, 1979). Flagellar antigens first described by Paterson (1939) contribute to this serotyping. In cross-agglutination tests using washed formol-killed cells of five serotypes of $L$. monocytogenes sensu lato grown at $25^{\circ} \mathrm{C}$ and unabsorbed antiserum, Paterson demonstrated a common flagellar antigen designated antigen B. A further three flagellar antigens (A, C and D) were variably present. In the same study monospecific antisera against factors $\mathrm{A}, \mathrm{C}$, and D were used to analyse a total of 27 isolates which all fell into one or other of three antigen combinations, namely $\mathrm{AB}, \mathrm{ABC}$ and $\mathrm{BD}$.

In the ensuing years no other method of antigenic analysis of L. monocytogenes flagella has been undertaken, and no further antigen combinations have been determined. Thirteen of the seventeen serotypes defined by agglutination bear the ABC combination (Seeliger \& Hohne, 1979). The serotypes comprising L. monocytogenes sensu lato were redefined by Rocourt et al. (1982) on the basis of DNA/DNA hybridization studies to include five genomic groups, only one of which is now known as L. monocytogenes (L. monocytogenes sensu stricto). As a result of that study, serotype 5 was redesignated $L$. ivanovii. This paper reports the comparison of the crude

Abbreviation: CFE, crude flagellar extract. 
flagellar extracts (CFEs) from $L$. ivanovii and seven serotypes of $L$. monocytogenes using SDSPAGE and immunoblotting. A polyclonal monospecific antibody and a monoclonal antibody, both directed against purified flagellin of serotype $4 \mathrm{~b}$, were used to detect antigenic similarities between the CFEs.

\section{METHODS}

Bacteria. L. monocytogenes serotypes $4 \mathrm{a}(768 / 88)$ and $4 \mathrm{~b}(787 / 88)$ were isolated from the brains of sheep with listeric encephalitis. Serotypes $1 / 2 \mathrm{~b}(788 / 88), 3 \mathrm{~b}(789 / 88), 3 \mathrm{c}(790 / 88), 4 \mathrm{~d}(791 / 88), 7(799 / 88)$ and $L$. ivanovii (793/88), were obtained from Mr M. Gitter, Central Veterinary Laboratory, Weybridge, Surrey, UK. All strains were stored on Dorset egg agar slopes. L. ivanovii was differentiated from L. monocytogenes sensu stricto strains on the basis of a positive CAMP test (with Rhodococcus equi) and the fermentation of D-xylose. Bacteria were grown at $20^{\circ} \mathrm{C}$ in tryptic soy broth (TSB, Gibco), without shaking, to the stationary phase of growth ( $\left.24 \mathrm{~h}\right)$. Cultures were stored by lyophilization in skimmed milk.

Preparation of CFEs. Bacteria (1 litre cultures) grown at $20^{\circ} \mathrm{C}$ were harvested by centrifugation at $5000 \mathrm{~g}$, washed twice in phosphate-buffered saline (PBS : $0.01 \mathrm{M}$-sodium phosphate, $0.15 \mathrm{M}$-sodium chloride; $\mathrm{pH} 7 \cdot 4$ ), and resuspended in $5 \mathrm{ml}$ PBS. Volumes $(5 \mathrm{ml})$ of this bacterial suspension were added to stoppered glass universal bottles together with 12 glass beads ( $2 \mathrm{~mm}$ diameter). The bottles were clamped vertically on a microid wristaction flask shaker (Griffin \& George) and shaken vigorously for $30 \mathrm{~min}$ at $20^{\circ} \mathrm{C}$. The bacterial suspension was centrifuged at $5000 \mathrm{~g}\left(4^{\circ} \mathrm{C}\right)$ for $30 \mathrm{~min}$ and the supernate retained. The bacterial pellet was washed twice with PBS by vigorous pipetting to remove sheared flagella trapped within the cell mass. The supernate and cell washings were pooled and centrifuged at $14000 \mathrm{~g}\left(4^{\circ} \mathrm{C}\right)$ for $40 \mathrm{~min}$ to clear remaining bacteria. The supernate from this final centrifugation represented the CFE, which was heated in a water bath for $60 \mathrm{~min}$ at $60^{\circ} \mathrm{C}$, and stored at $-20^{\circ} \mathrm{C}$. The protein content of each CFE was determined (Peel et al., 1988) and adjusted so that a standard protein loading of each CFE could be applied to gels.

SDS-PAGE and Western blotting. The protocols and reagents used were as described by Peel et al. (1988). Western blots were developed using $(a)$ an affinity-purified rabbit antibody, and $(b)$ a mouse monoclonal antibody (isotype IgG2). Both antibodies were directed against $29 \mathrm{kDa}$ flagellin of serotype $4 \mathrm{~b}$.

In some experiments SDS-PAGE was done using pre-stained molecular mass markers (Sigma) and prolonging electrophoresis until chymotrypsinogen $A(25.7 \mathrm{kDa})$ had reached the bottom of the gel. This took approximately $6 \mathrm{~h}$, twice the time normally taken for electrophoresis.

Biotin-avidin peroxidase technique. For enhanced staining of Western blots using monoclonal antibody, a biotinavidin amplification step was used (Sera-Lab, Sussex). Mouse antibody was followed by incubation with an affinity-purified biotinylated horse anti-mouse IgG immunoglobulin, which was succeeded by incubation with avidin D conjugated to horse-radish peroxidase. Incubation steps were for $1 \mathrm{~h}$ at $37^{\circ} \mathrm{C}$. The enzyme substrate was diaminobenzidine.

Dot-blotting. For dot-blots, $0.5 \mu \mathrm{g}$ quantities of crude flagellar protein were applied directly to nitrocellulose, allowed to air dry and developed with polyclonal or monoclonal antibody as for Western blots.

Electron microscopy. Electron microscopy was performed on $L$. monocytogenes serotypes $4 \mathrm{a}, 4 \mathrm{~b}$ and 7 , and $L$. ivanovii, as described by Peel et al. (1988).

Estimation of protein and molecular mass. The methods were those described by Peel et al. (1988).

\section{RESULTS}

Comparison of L. monocytogenes serotypes $4 a, 4 b$ and 7 , and L. ivanovii, by transmission electron microscopy

When late-exponential-phase broth cultures grown at $20^{\circ} \mathrm{C}$ were examined by electron microscopy no differences were observed between $L$. monocytogenes serotypes $4 \mathrm{a}$ and $4 \mathrm{~b}$ and $L$. ivanovii with regard to structure, quantity or distribution of flagella. However, no flagella were visible on L. monocytogenes serotype 7 cells (data not shown).

\section{Comparison of CFE by SDS-PAGE, silver staining and Western blotting}

When the CFEs of L. monocytogenes serotypes $1 / 2 \mathrm{~b}, 3 \mathrm{~b}, 3 \mathrm{c}, 4 \mathrm{a}, 4 \mathrm{~b}, 4 \mathrm{~d}$ and 7 , and of $L$. ivanovii, were run in SDS-PAGE and stained with silver, the prominent protein band observed in all strains except serotype 7 had a molecular mass in the region of $29 \mathrm{kDa}$ (Fig. 1a,b). This was similar to the molecular mass already described for type $4 \mathrm{~b}$ flagellin (Peel et al., 1988). It was not clear from the gel shown in Fig. $1(a)$ exactly how much presumptive flagellin was expressed by 


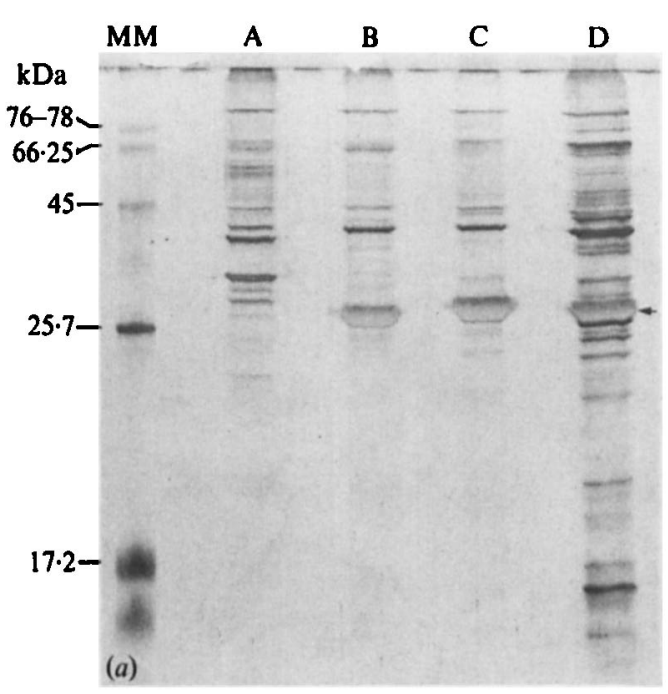

Fig. 1. SDS-PAGE and silver stain of CFEs ( $a$, protein loaded at $5 \mu \mathrm{g}$ per lane; $b$, protein loaded at $0.5 \mu \mathrm{g}$ per lane) of $L$. monocytogenes serotypes 7 (lane A), $4 b(C), 4 a(D), 4 b$ (E), 4d (F), 3c (G), 1/2b (H) and $3 b(\mathrm{I})$, and of $L$. ivanovii (B). The arrows denote the position of $29 \mathrm{kDa}$ flagellin polypeptides. Note the slight difference in molecular mass between flagellin of serotype $3 c$ (lane $G$ ) and the four other serotypes in $(b)$. MM, molecular mass markers.

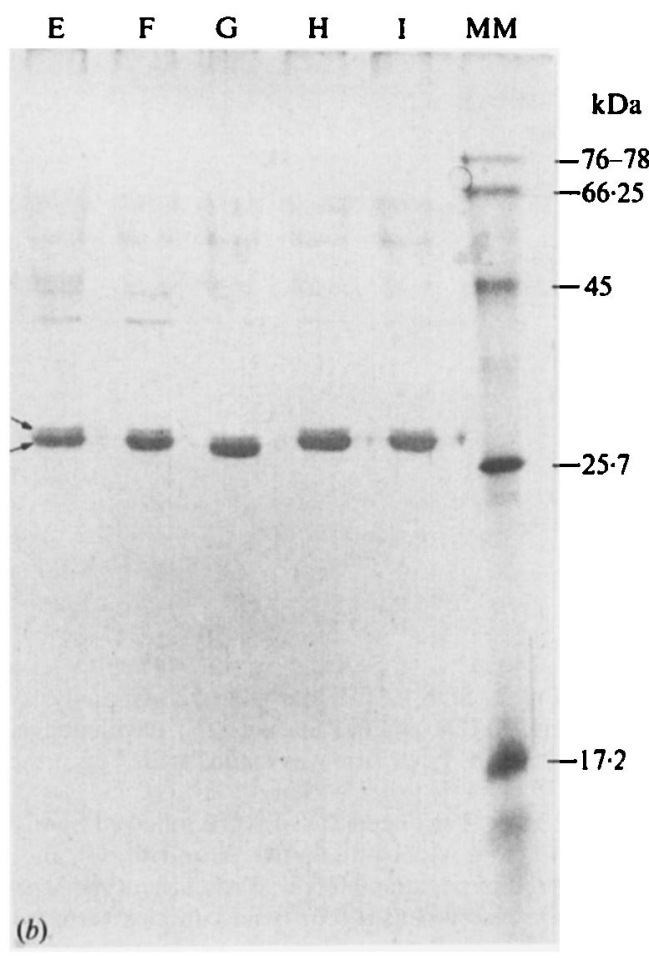

serotype 7, but only a minor protein was present in the $29 \mathrm{kDa}$ region for this serotype (lane A). In a Western blot of CFEs from serotypes $4 \mathrm{a}, 4 \mathrm{~b}$ and 7 and $L$. ivanovii an affinity-purified antibody against serotype $4 \mathrm{~b}$ flagellin reacted strongly with $29 \mathrm{kDa}$ polypeptides of serotypes $4 \mathrm{a}$, $4 \mathrm{~b}$, and $L$. ivanovii whereas no polypeptides could be detected in serotype 7 (Fig. 2).

The results of SDS-PAGE (Fig. $1 a$ ), showed serotypes $4 \mathrm{a}$ and $4 \mathrm{~b}$ and $L$. ivanovii to have approximately the same amount of $29 \mathrm{kDa}$ material per $\mu \mathrm{g}$ of loaded protein, and that the presumptive flagellin was composed of two closely migrating polypeptides. The proteins stripped from each of the strains shown in Fig. 1(b) contained a similar proportion of flagellin, and the double banding of the $29 \mathrm{kDa}$ complex was more obvious. An additional observation from Figs $1(a), 1(b)$ and 2 was that the flagellins of serotype $3 \mathrm{c}$ and $L$. ivanovii had slightly lower molecular masses than those of the six other serotypes examined. Calculations showed that the molecular mass of serotype $3 \mathrm{c}$ flagellin was approximately $1 \mathrm{kDa}$ lower than those of the other serotypes shown in Fig. 1(b).

Prolonged electrophoresis was used to determine whether subtle differences in molecular mass existed between flagellins of different serotypes. Application of this technique to serotypes $1 / 2 b, 3 b, 4 d$ and $4 \mathrm{~b}$ resolved each flagellar preparation into three rather than two distinct bands. Again the flagellin of serotype $3 \mathrm{c}$ had an apparently lower molecular mass. Prolonged coelectrophoresis of serotype $4 \mathrm{~b}$ CFE together with CFE of serotype $1 / 2 \mathrm{~b}, 3 \mathrm{~b}$ or $4 \mathrm{~d}$ yielded a threepolypeptide complex, as seen following prolonged electrophoresis of individual serotypes (Fig. 3). However, when serotype $3 \mathrm{c}$ CFE was co-electrophoresed with that of serotype $4 \mathrm{~b}$ an extra band was obtained (Fig. 3, lane C), confirming differences in molecular mass of at least one of the polypeptide components; similar results were obtained when $L$. ivanovii CFE was coelectrophoresed with $4 \mathrm{~b}$ CFE.

Monoclonal antibody to serotype $4 \mathrm{~b}$ flagellin reacted against flagellins of all serotypes except $3 \mathrm{c}$ and 7 , and $L$. ivanovii. Polyclonal antibody reacted with all CFEs tested (Fig. $4 a, 4 b$ ). 


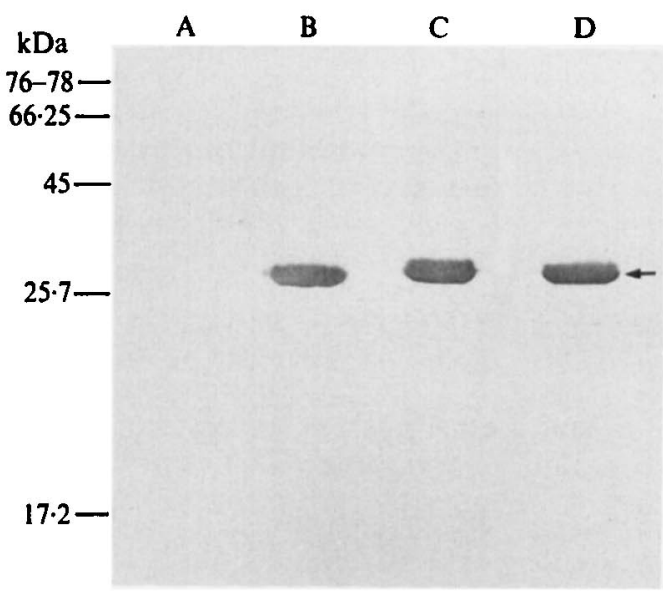

Fig. 2

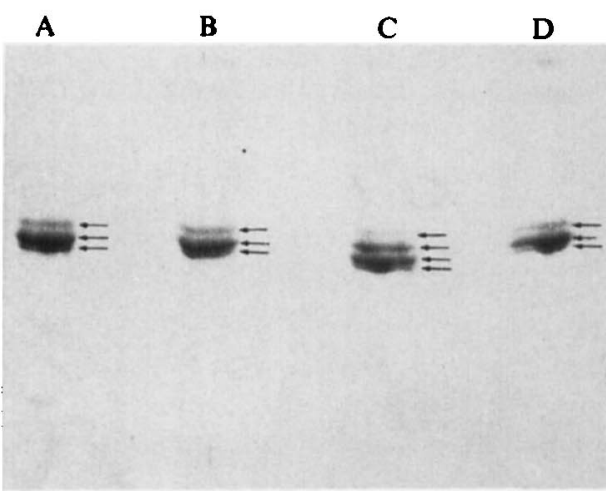

Fig. 3

Fig. 2. SDS-PAGE and Western blot analysis of CFEs of $L$. monocytogenes serotypes 7 (lane A), $4 \mathrm{~b}$ (C) and $4 \mathrm{a}(\mathrm{D})$, and of $L$. ivanovii (B), developed using affinity-purified antibody raised against serotype $4 \mathrm{~b}$ flagellin. Each lane was loaded with $5 \mu \mathrm{g}$ protein. The arrow denotes the position of $29 \mathrm{kDa}$ flagellin.

Fig. 3. Prolonged SDS-PAGE followed by silver staining of the combined CFEs of serotypes $1 / 2 \mathrm{~b}$ and $4 b$ (lane A), $3 b$ and $4 b(B), 3 c$ and $4 b(C)$, and $4 d$ and $4 b(D)$. Each component was loaded at $0.5 \mu g$ of protein per lane. Note that when serotype $3 c$ is mixed with serotype $4 b$ (lane $C$ ) the combined flagellins are resolved as a four-band complex (arrows).

(a)

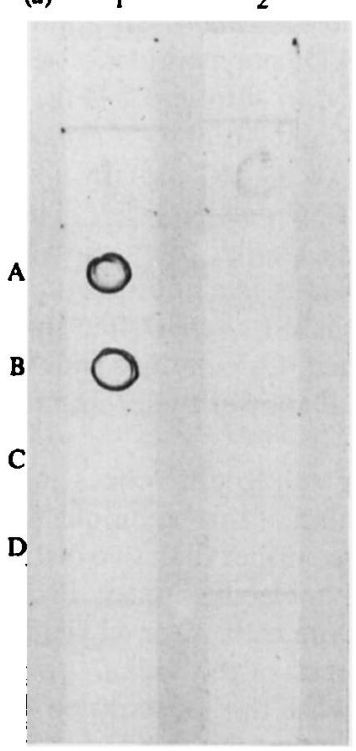

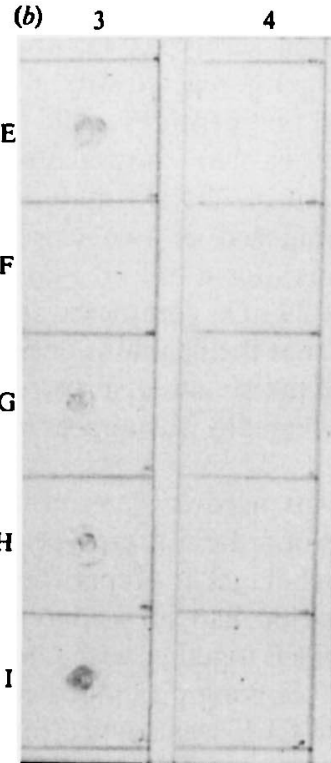

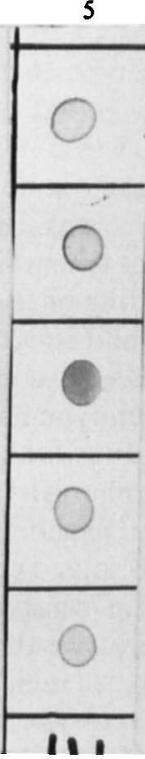

6

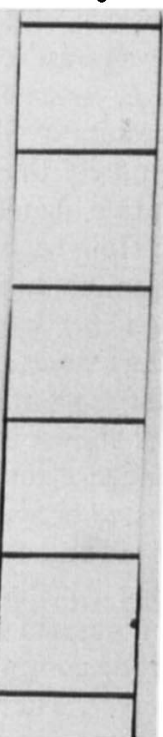

Fig. $4(a, b)$. Dot-blots of crude flagellar extracts of serotype 4a (dot A), 4b (B), L. ivanovii (C), 7 (D), 4d $(\mathrm{E}), 3 \mathrm{c}(\mathrm{F}), 3 \mathrm{~b}(\mathrm{G}), 1 / 2 \mathrm{~b}(\mathrm{H})$ and $4 \mathrm{~b}(\mathrm{I})$ developed with : $(1,3)$ mouse monoclonal antibody to serotype $4 \mathrm{~b}$ flagellin followed by anti-mouse IgG horse-radish peroxidase (HRP) conjugate; $(2,4)$ anti-mouse HRP conjugate alone; (5) affinity-purified rabbit anti-flagellin antibody plus anti-rabbit HRP conjugate, (6) anti-rabbit HRP conjugate alone. Antigen applied at $0.5 \mu \mathrm{g}$ protein per spot. 
A

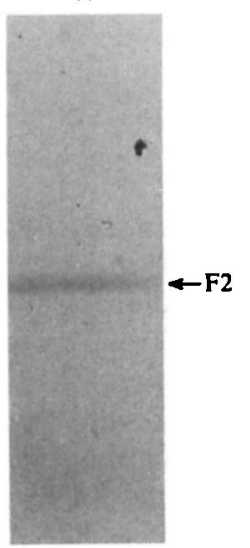

B

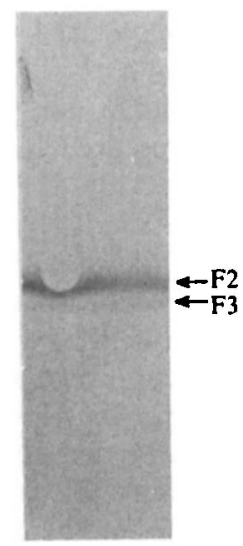

C

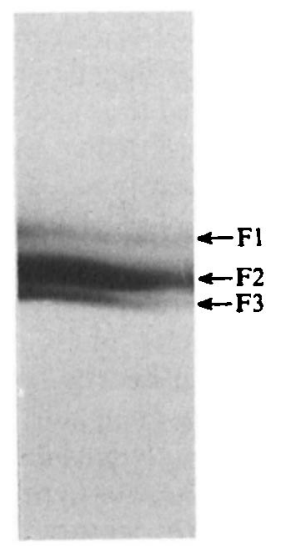

Fig. 5. SDS-PAGE and Western blot analysis of crude flagellar extracts of serotype $1 / 2 b$ developed with (A) monoclonal antibody, (B) monoclonal antibody followed by biotinylated anti-mouse IgG, and (C) affinity-purified rabbit anti-flagellin antibody. Note that one, two and three bands, denoted by arrows, are visible in strips $A, B$ and $C$ respectively.

The most successful separation of the three flagellar bands (F1, F2, F3) was effected by prolonged electrophoresis through a $12 \%$ resolving gel. The well loading compatible with maximum resolution of the throe bands of type $1 / 2 \mathrm{~b}$ flagellin was low $\left(0.5 \mu \mathrm{g}\right.$ per $\mathrm{mm}^{2}$ gel area) but readily detected in Western blots by the affinity-purified rabbit anti-flagellin antibody (Fig. 5, lane C). The monoclonal antibody clearly detected the middle band, F2 (Fig. 5, lane A), and further scrutiny revealed a much fainter band of lower molecular mass corresponding to F3. This was confirmed when a further strip was developed using monoclonal antibody enhanced with biotin-avidin, in which both F2 and F3 bands were detected and F1 remained unstained (Fig. 5, lane B).

\section{DISCUSSION}

The flagellins of $L$. monocytogenes serotypes $1 / 2 \mathrm{~b}, 3 \mathrm{~b}, 4 \mathrm{a}, 4 \mathrm{~b}$ and $4 \mathrm{~d}$ can be distinguished from the flagellins of slightly lower molecular mass of serotype $3 \mathrm{c}$ and L. ivanovii by SDS-PAGE. In addition, the results obtained by immunoblotting using a monoclonal antibody directed against serotype $4 \mathrm{~b}$ flagellin provide evidence for an antigenic difference between the flagellins of serotypes $3 \mathrm{c}$ and $L$. ivanovii and the other serotypes examined.

The differences in flagellar structure and antigenicity observed for serotype $3 \mathrm{c}$ are not unexpected as the traditional agglutination test assigns a $\mathrm{BD}$ antigenic profile to it while the rest of the strains examined have an ABC antigen composition (Ivanov, 1962; Seeliger \& Hohne, 1979). Although $L$. ivanovii has an ABC antigenic combination (Ivanov, 1962) the differences observed here between it and the other $L$. monocytogenes serotypes reflect its recent redesignation as a separate species.

Extended electrophoresis revealed the flagellin preparation to be composed of three distinct bands. A reasonable interpretation of this observation is that the F1 protein, with the highest molecular mass, represents flagellin and that the two proteins of lower molecular mass, F2 and F3, represent modifications of flagellin brought about by proteolytic action of bacterial proteases acting at the terminal $-\mathrm{COOH}$ or $-\mathrm{NH}_{2}$ ends of $29 \mathrm{kDa}$ flagellin, and released from organisms during the shearing stage of flagellar harvest. However, the result obtained using monoclonal antibody suggests that the $F 1$ and F2 components are unrelated proteins, and thus it is unlikely that the $\mathrm{F} 2$ protein has been derived by proteolytic digestion of the larger $\mathrm{F} 1$ component. The presence of the epitope bound by the monoclonal antibody in the F2 and F3 components suggests that $\mathrm{F} 3$ could be a closely related modified product of F2. 
From the electron microscopic examination of whole organisms and SDS-PAGE of crude extracts it is concluded that the serotype 7 isolate used in this study does not elaborate surface flagellins. The absence of flagella from serotype 7 is probably not remarkable since other workers have demonstrated the existence of stable, non-flagellated variants of $L$. monocytogenes (Leifson \& Palen, 1955). Further work is required to determine whether aflagellation is a common feature of this serotype.

In conclusion, an affinity-purified monospecific polyclonal antibody raised by inoculation of $29 \mathrm{kDa}$ flagellin of $L$. monocytogenes serotype $4 \mathrm{~b}$ was equally able to detect flagellins of six other flagellate serotypes, including representatives of the serogroups commonly isolated from pathogenic material, viz. $1 / 2$ and 4 , and $L$. ivanovii. However, flagellins of serotype $3 \mathrm{c}$ and $L$. ivanovii could be distinguished by (1) a lower molecular mass, and (2) lack of reaction with monoclonal antibody raised against serotype $4 \mathrm{~b}$ flagellin. Using a battery of monoclonal antibodies, Newell $(1986 a, b)$ postulated six different epitopes on the flagella of Campylobacter jejuni, and described the serotype specificity of such monoclonal antibodies and the development of an ELISA capture technique for the detection of flagellar antigen in faecal material. In our study, an epitopic difference between serotypes of $L$. monocytogenes could be detected using a single monoclonal antibody. This gives some optimism that a panel of monoclonal antibodies would reveal other differences which could be exploited in an alternative method of serotyping.

We thank Mr J. Menzies and Mr A. Dawson for technical assistance. M. Peel was the recipient of an AFRC veterinary postgraduate study award.

\section{REFERENCES}

Gray, M. L. \& Killinger, A. H. (1966). Listeria monocytogenes and listeric infections. Bacteriological Reviews 30, 309-382.

IVANov, I. (1962). Untersuchungen über die Listeriose der Schafe in Bulgarien. Monatshefte für Veterinar Medizin 17, 729-736.

Leifson, E. \& Palen, M. I. (1955). Variations and spontaneous mutations in the genus Listeria in respect to flagellation and motility. Journal of Bacteriology 70, 233-240.

Newell, D. G. (1986a). Monoclonal antibodies directed against the flagella of Campylobacter jejuni: production, characterization and lack of effect on the colonization of infant mice. Journal of Hygiene 96, 131-141.

Newell, D. G. (1986b). Monoclonal antibodies directed against the flagella of Campylobacter jejuni:

cross reactivity, serotype specificity and potential use in diagnosis. Journal of Hygiene 96, 377-384.

PAterson, J. S. (1939). Flagellar antigens of organisms of the genus Listerella. Journal of Pathology and Bacteriology 48, 25-32.

Peel, M., Donachie, W. \& Shaw, A. (1988). Temperature-dependent expression of flagella of Listeria monocytogenes studied by electron microscopy, SDSPAGE and Western blotting. Journal of General Microbiology 134, 2171-2178.

Rocourt, J., Grimont, F., Grimont, P. A. D. \& SEeliger, H. P. R. (1982). DNA relatedness among serovars of Listeria monocytogenes sensu lato. Current Microbiology 7, 383-388.

Seeliger, H. P. R. \& Hohne, K. (1979). Serotyping of Listeria monocytogenes and related species. Methods in Microbiology 13, 31-49. 